\title{
Statistical Evaluation of Influence of Polymers Concentration on Disintegration Time and Diazepam Release from Quick Disintegrating Rapid Release Tablet
}

\author{
Tapan Kumar GIRI and Biswanath SA* \\ Centre for Advanced Research in Pharmaceutical Sciences, Department of Pharmaceutical \\ Technology, Jadavpur University, Kolkata-700032, India
}

(Received January 19, 2009; Accepted May 1, 2009)

\begin{abstract}
This study describes the formulation of rapidly disintegrating, fast dissolving diazepam tablets intended for use in the oral cavity. The tablets were prepared by the conventional wet granulation method using solid dispersion of the drug with PEG-4000 and/or PEG-6000. A $3^{2}$ factorial design was used to reduce the number of experimental runs and to obtain several formulations by which tablets disintegrated within 3 min and released $85 \%$ of the drug in less than 30 min. Several tablet formulations prepared with different amounts of PEGs in solid dispersion met the above two criteria. However, tablets which were prepared with PEG-4000 alone at the lowest concentration disintegrated in the shortest time $(32.12 \mathrm{sec})$ and released $85 \%$ of the drug most rapidly $(11.03 \mathrm{~min})$.
\end{abstract}

Key words_ _ fast dissolving tablet; factorial design; optimization; solid dispersion; diazepam; polyethylene-glycol (PEG)

\section{INTRODUCTION}

The search for alternative routes of drug delivery has led to exploration of various mucosae as possible routes of drug delivery for systemic action. Since the invention of nitroglycerin sublingual tablets, interest has been generated in academia and pharmaceutical industries to use the oral mucosal route as a substitute delivery approach. The highly vascularized nature and rich blood supply in oral mucosa ${ }^{1)}$ provide faster onset of action of drugs. ${ }^{2)}$ Moreover several constraints such as difficulty in swallowing experienced by many paediatrics and geriatrics, ${ }^{3)}$ and in chewing by edentulous; ${ }^{4)}$ nausea and vomiting experienced with certain drugs when released in stomach;5) degradation and metabolism of susceptible drugs in gastrointestinal tract; ;) tissue necrosis and irritation from repeated administration of parenterals, ${ }^{7)}$ high expenses due to sterile manufacturing ${ }^{8)}$ are avoided through oromucosal delivery of drugs. As a result, attention is being given to developing rapidly disintegrating, fast dissolving oral tablet dosage forms of drugs.

After release from such tablets, the drug dissolves in saliva and then partitions into the oral mucous membrane. Thus permeability of a drug through the membrane depends on the amount and rate of drug

*e-mail: biswanathsa2003@yahoo.com released from the tablet and the drug's solubility in the saliva. Therefore, two principal criteria appear to be important for developing rapidly disintegrating and fast dissolving tablets: 1) disintegration of preferably $<3 \min ^{9)}$ and 2) rapid drug dissolution: time required for $85 \%$ dissolution $\left(\mathrm{t}_{85}\right)$ of less than 30 min. ${ }^{10)}$ Valuable research reports for formulation of rapidly disintegrating tablets are available; ${ }^{11)}$ also, various technologies for improving dissolution property of poorly water soluble drugs have been documented to enhance bioavailability following oral absorption. ${ }^{12)}$ Solid dispersion with polyethylene glycols (PEGs) is one of the methods for increasing solubility and hence the rate of dissolution of poorly water soluble drugs. ${ }^{13,14)}$ However, compression of such solid dispersions into tablet dosage form tends to protract the disintegration time of the tablet. ${ }^{15)}$ It is therefore necessary to optimize the amount of PEGs which can provide rapid dissolution of a drug without prolonging the disintegration time of the tablet. Such optimization requires a large number of experimental trials.

The objective of the present work was to develop a rapidly disintegrating, fast dissolving tablet of diazepam using a small number of experimental runs. Use of a $3^{2}$ factorial design was attempted to generate an optimized region in the superimposed contour plot where any combination of PEGs could provide rapid disintegration $(\mathrm{DT}<3 \mathrm{~min})$ of the tablets and rapid 
dissolution $\left(\mathrm{t}_{85 \%}<30 \mathrm{~min}\right)$ of the drug contained therein. Diazepam, which is included in the 'WHO Essential Drug List' is indicated for convulsion/ epileptic seizure, anxiety and sleep disorder and preoperative medication. ${ }^{16-19)}$ Intravenous therapy with diazepam requires great care and caution to avoid thrombophlebitis and irritation. ${ }^{20)}$ Absorption from the intramuscular route is poor and erratic, ${ }^{21)}$ although absorbed well following oral administration, the time to reach peak plasma concentration is 1 -2 h. ${ }^{22)}$ Delay in treatment beyond $30 \mathrm{~min}$ in epileptic seizure may cause serious damage to the patient. ${ }^{19)}$ If diazepam is formulated in a rapidly disintegrating, fast dissolving tablet dosage form, it could enable a patient for self medicate even without the aid of water in a situation where onset of convulsion is apprehended.

\section{MATERIALS}

Diazepam (East India Pharmaceutical Works, Ltd., Kolkata, India), Croscarmellose sodium (Acdisol), maize starch, saccharin-Na [Dey's Medical Stores (Mfg.) Ltd., Kolkata], microcrystalline cellulose(Avicel, PH-102) [Dr. Reddy's Laboratory, Hyderabad, India] were obtained as gift samples. Polyethylene glycol-6000 (Qualigen, Mumbai, India), polyethylene glycol-4000 (Merck, Limited, Mumbai), lactose monohydrate (Merck, India), magnesium stearate and all other ingredients were obtained commercially and used as received.

\section{METHODS}

Phase Solubility Study Solubility measurements of diazepam were performed by adding excess amount of drug to $10 \mathrm{ml}$ of double distilled water containing a fixed amount of carrier $(10 \% \mathrm{w} / \mathrm{v})$ or carrier mixture $(5 \%+5 \%)$ in stoppered conical flasks. Phase solubility studies were carried out by adding excess amounts of drug to $10 \mathrm{ml}$ of aqueous solution containing increasing amounts of each carrier $(0-10 \%)$, in stoppered conical flasks. In both series of experiments, the flasks were shaken at 50 revolutions per min in a shaking incubator (Model KMC 8480 SL, Vision Scientific Company, Ltd., Seoul, South Korea) at $37 \pm 0.5^{\circ} \mathrm{C}$ until equilibrium (about $90 \mathrm{~h}$ ) was reached. The resulting mixtures were filtered and aliquots, following suitable dilutions, were analyzed using a spectrophotometer (Genesyis, $10 \mathrm{UV}$, Thermo Electron Corporation,
Wisconsin, USA) at $230 \mathrm{~nm}$ to determine solubilities of diazepam in different media. Each experiment was performed three times (coefficient of variation $[\mathrm{CV}]$ $<2 \%)$.

Preparation of Solid Dispersion Diazepam solid dispersions of both binary and ternary systems were prepared by conventional fusion method using PEG-4000 and/or PEG-6000 as carrier. In the binary system, the solid dispersions of $1: 2.5$ and $1: 5 \mathrm{wt} /$ wt of drug to carrier were prepared. In the ternary system, the solid dispersions of $1: 2.5: 2.5,1: 2.5:$ 5 and $1: 5: 5 \mathrm{wt} / \mathrm{wt}$ of drug to carrier were prepared. Accurately weighed amounts of diazepam and carriers in different ratios were heated at $134^{\circ} \mathrm{C}$ in an oil bath with continuous stirring until a homogeneous melt was obtained and then cooled to room temperature and dried in vacuum desiccators over fused $\mathrm{CaCl}_{2}$ for $72 \mathrm{~h}$. After complete dryness, the diazepam solid dispersions were pulverized with mortar-pestle and sieved through a British Standard sieve No. 44. The solid dispersions were stored at room temperature in hermetically sealed glass containers until use.

Preparation of Tablets by Wet Granulation The raw materials were passed through a No. 44 screen prior to mixing. Diazepam (as such or in solid dispersion), microcrystalline cellulose, lactose, and an intragranular fraction of croscarmellose sodium was mixed. Starch paste was added to the mixture to wet the mass. The wet mass was then passed through a No. 18 screen and the resulting granulation was dried in a hot air oven at $40^{\circ} \mathrm{C}$ for $2 \mathrm{~h}$. The dried granules were passed through a No. 22 screen, mixed with extragranular fraction of croscarmellose sodium and lubricated with magnesium stearate. The final powder blend was then compressed into tablets using concave punches (approx. $9.5 \mathrm{~mm}$ diameter) in a 10 station mini press tablet machine (RIMEK, Karnavati Engineering, Ltd; Gujrat, India). The compression force was kept constant for all formulations to eliminate its effect on dissolution.

Disintegration Test Disintegration time of tablets was measured using a modified disintegration test method. ${ }^{23)}$ Water $(10 \mathrm{ml})$ was placed in a Petri dish and a tablet was carefully placed in the centre and agitated mildly. Time required for complete disintegration of the tablet into fine particles was noted.

Dissolution Test In vitro release of diazepam from the tablets was studied in a USP phosphate buffer solution $(500 \mathrm{ml}, \mathrm{pH} 5.8)$ at $37 \pm 0.5^{\circ} \mathrm{C}$ and 50 
rpm using USP II dissolution test apparatus (model TDP-06P, Electrolab, Mumbai). Aliquots $(10 \mathrm{ml})$ were removed from the dissolution medium at specified time intervals and replenished immediately with the same volume of fresh medium, following suitable dilution, aliquots, were analyzed spectrophotometrically at $230 \mathrm{~nm}$.

Factorial Design/Statistical Design A $3^{2}$ full factorial design was constructed to determine the effect of the amounts of PEG-4000 $\left(\mathrm{X}_{1}\right)$ and amount of PEG-6000 $\left(\mathrm{X}_{2}\right)$ on the DT and $\mathrm{t}_{85 \%}$. Each factor was tested at three levels designated as $-1,0$ and +1 . The levels of the two factors were selected on the basis of preliminary experiments carried out before constructing the factorial design. All other formulations and manufacturing variables were kept constant throughout the study. The software Statgraphics Plus $3.0^{\circledR}$ was used for generating the experimental design, modeling the response surface and calculating the statistical evaluation.

\section{RESULTS AND DISCUSSION}

Rapidly disintegrating fast dissolving tablets of diazepam were prepared using either diazepam or solid dispersion of diazepam with various amounts of PEG-4000 and/or PEG-6000 (Table 1) by wet granulation method. The physical characteristics of the tablets were as follows: hardness (measured using a Monsanto hardness tester), $2 \mathrm{Kg} / \mathrm{cm}^{2}$; friability (determined using a friabilator, Veego, Mumbai), 0.08$0.35 \%$; and potency (determined following the method of Indian Pharmacopoeia, 1996) , $4.98 \pm 0.08$ $\mathrm{mg}$. Formulation of rapidly disintegrating fast dissolving tablets is based on two principal criteria: the tablets should disintegrate in less than $3 \mathrm{~min}$ and $85 \%$ of the drug should dissolve in less than $30 \mathrm{~min}$. Although solid dispersion with PEG increases the solubility and hence the rate of dissolution of water insoluble drugs, it also protracts the disintegration time of a tablet.

To optimize the ratios of PEGs in solid dispersion that can provide rapid disintegration of tablets with rapid dissolution of the drug contained therein, 9 formulations were prepared according to the $3^{2}$ factorial design (Table 2). The design provided an empirical second order polynomial model. Regression polynomials for the individual dependent variables (DT and $t_{85 \%}$ ) were calculated and applied to approximate the surface responses and contour plots.
Table 1. Composition of Diazepam Tablets $(300 \mathrm{mg})$

\begin{tabular}{l|l}
\hline \multicolumn{1}{c|}{ Ingredient } & \multicolumn{1}{c}{ Quantity (mg) } \\
\hline Diazepam & $5 \mathrm{mg}$ \\
\hline PEG-4000 & 0 to $25 \mathrm{mg}$ \\
\hline PEG-6000 & 0 to $25 \mathrm{mg}$ \\
\hline Avicel, PH-102 & $126 \mathrm{mg}$ \\
\hline Starch & $10 \mathrm{mg}$ \\
\hline Crosscarmellose $\mathrm{Na}$ & $15 \mathrm{mg}$ \\
\hline Magnesium stearate & $1 \mathrm{mg}$ \\
\hline Lactose & Quantity sufficient to $300 \mathrm{mg}$ \\
\hline
\end{tabular}

Table 2. Composition and Responses for a $3^{2}$ Factorial Design

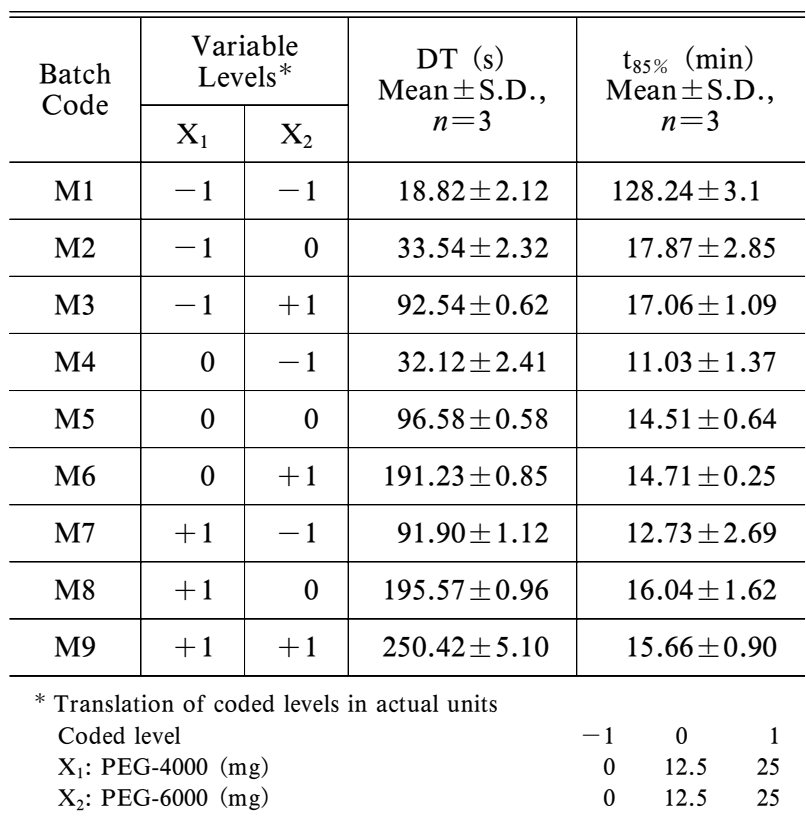

The general model (Equation 1) was generated to fit the various data.

$$
\mathrm{Y}=\mathrm{b}_{0}+\mathrm{b}_{1} \mathrm{X}_{1}+\mathrm{b}_{2} \mathrm{X}_{2}+\mathrm{b}_{12} \mathrm{X}_{1} \mathrm{X}_{2}+\mathrm{b}_{11} \mathrm{X}_{1}^{2}+\mathrm{b}_{22} \mathrm{X}_{2}^{2}
$$

where $\mathrm{Y}=$ Dependent variable $\left(\mathrm{DT}\right.$ or $\left.\mathrm{t}_{85 \%}\right)$.

$\mathrm{X}_{1}=$ Amount of PEG-4000

$\mathrm{X}_{2}=$ Amount of PEG-6000

$b_{0}, b_{1}, b_{2}, b_{11}, b_{12}$ and $b_{22}$ represent regression coefficients of the independent variable $\left(\mathrm{X}_{1}, \mathrm{X}_{2}\right)$. The main effects $\left(\mathrm{X}_{1}\right.$ and $\left.\mathrm{X}_{2}\right)$ represent the average result of changing one factor at a time from its low to high value. The interaction term $\left(\mathrm{X}_{1}\right.$ and $\left.\mathrm{X}_{2}\right)$ shows the changes in response when two factors are simultaneously changed. The polynomial terms $\left(X_{1}^{2}\right.$ and $\left.X_{2}^{2}\right)$ are included to investigate nonlinearity. 
Disintegration time of 9 formulations prepared according to the factorial design were measured and put in Equation 1, and a full model polynomial equations (Equation 2) was generated by carrying out multiple linear regression to quantitatively explain the effect of independent variable (amount of PEG) on DT.

$$
\begin{aligned}
\mathrm{DT}= & 103.791+65.4983 \mathrm{X}_{1}+65.225 \mathrm{X}_{2}+7.155 \mathrm{X}_{1}^{2} \\
& +4.275 \mathrm{X}_{2}^{2}+21.2008 \mathrm{X}_{1} \mathrm{X}_{2}
\end{aligned}
$$

The results of multiple linear regression analysis and analysis of variance (ANOVA) are represented in Table 3. Since the significance level of the coefficients $\mathrm{b}_{11}$ and $\mathrm{b}_{22}$ was greater than $p=0.05$, they were omitted from the full model and a reduced model (Equation 3) was generated.

$$
\begin{aligned}
\mathrm{DT}= & 111.411+65.4983 \mathrm{X}_{1}+65.225 \mathrm{X}_{2} \\
& +21.2008 \mathrm{X}_{1} \mathrm{X}_{2}
\end{aligned}
$$

The positive sign of $b_{1}, b_{2}$ and $b_{12}$ indicate that increase in the concentration of either PEG-4000 or PEG-6000 or both will increase the DT of a tablet. Table 2 shows that DT of tablets prepared with 12.5 mg of PEG-4000 is higher than that of the tablets prepared without PEG-4000. Increase in the amount of PEG-4000 from $12.5 \mathrm{mg}$ to $25 \mathrm{mg}$ further increased the disintegration time. Similar results were obtained with the tablets prepared with PEG-6000. Although the DT of tablets prepared with PEG-6000 appeared to be marginally higher than that of those prepared with PEG-4000, no significant difference at $95 \%$ confidence level was noted as observed by Student's $t$ test. However, use of PEG-4000 and PEG-6000 in combination in different ratios protracted the DT of the tablets considerably.

Increased disintegration time of the tablets prepared from solid dispersions is related to the soft and waxy nature of PEG-4000 and PEG-6000. Such carriers essentially act as a strong binder. During compression, the carriers could plasticize, soften or melt, filling the pores within tablets and subsequently increasing the DT of the tablet. ${ }^{15)} \mathrm{t}_{85 \%}$ of 9 formulations prepared according to the factorial design were measured and put in Equation 1 to generate a full model polynomial equation (Equation 4) which can explain quantitatively the effect of independent variable (amount of PEG) on $t_{85 \%}$.

$$
\begin{aligned}
t_{85 \%}= & 2.02-19.7917 \mathrm{X}_{1}-17.43 \mathrm{X}_{2}+21.1817 \mathrm{X}_{1}^{2} \\
& +17.0967 \mathrm{X}_{2}^{2}+28.5283 \mathrm{X}_{1} \mathrm{X}_{2}
\end{aligned}
$$

\begin{tabular}{|c|c|c|c|c|c|c|}
\hline Response $[\mathrm{DT}]$ & $\mathrm{b}_{0}$ & $\mathrm{~b}_{1}$ & $\mathrm{~b}_{2}$ & $\mathrm{~b}_{11}$ & $\mathrm{~b}_{12}$ & $b_{22}$ \\
\hline FM & 103.791 & 65.4983 & 65.225 & 7.155 & 21.2008 & 4.275 \\
\hline$p$ value & - & 0 & 0 & 0.2424 & 0.001 & 0.4802 \\
\hline $\mathrm{RD}$ & 111.411 & 65.4983 & 65.225 & - & 21.2008 & - \\
\hline \multirow[t]{2}{*}{$p$ value } & - & 0 & 0 & - & 0 & - \\
\hline & & DF & $\mathrm{SS}$ & MS & $\mathrm{F}$ & $\mathrm{R}^{2}$ \\
\hline \multirow[t]{2}{*}{ Regression } & FM & 5 & 159609.0 & 31921.7 & 150.37 & 0.9728 \\
\hline & $\mathrm{RD}$ & 3 & 159192.0 & 53063.9 & 250.36 & 0.9702 \\
\hline \multirow[t]{2}{*}{ Error } & FM & 21 & 4457.98 & 212.285 & - & - \\
\hline & $\mathrm{RD}$ & 23 & 4874.8 & 211.948 & & \\
\hline Response $\left[\mathrm{t}_{85 \%}\right]$ & $\mathrm{b}_{0}$ & $b_{1}$ & $b_{2}$ & $b_{11}$ & $b_{12}$ & $b_{22}$ \\
\hline \multirow{3}{*}{$\begin{array}{l}\mathrm{FM} \\
p \text { value }\end{array}$} & 2.02 & -19.791 & -17.43 & 21.1817 & 28.5283 & 17.096 \\
\hline & - & 0.0003 & 0.0009 & 0.0130 & 0 & 0.0398 \\
\hline & & DF & SS & MS & $\mathrm{F}$ & $\mathrm{R}^{2}$ \\
\hline \multirow{2}{*}{$\begin{array}{l}\text { Regression } \\
\text { Error }\end{array}$} & FM & 5 & 26731.4 & 5346.28 & 14.65 & 0.7771 \\
\hline & FM & 21 & 7665.27 & 365.013 & - & - \\
\hline
\end{tabular}

The results of multiple linear regression analysis and analysis of variance (ANOVA) are represented in Table 3. Since all the coefficients were significant at $p<0.05$, they were retained in the full model. The

Table 3. Summary of Results of Regression Analysis and ANOVA for Measured Response*

* FM indicates full model; RM, reduced model; $p$ value, the significance level; DF, degrees of freedom; SS, sum of squares; F, Fischers's ratio; $\mathrm{R}^{2}$, regression coefficient. 
negative sign of the coefficients $b_{1}$ and $b_{2}$ indicates that increase in the amount of PEG, when used alone, will decrease $\mathrm{t}_{85 \%}$. Table 2 shows that incorporation of $12.5 \mathrm{mg}$ of either PEG-4000 or PEG-6000 drastically reduced $t_{85 \%}$ when compared with that from the tablets prepared without solid dispersion. Similar observation in $\mathrm{t}_{85} \%$ was noted with the tablets prepared with $25 \mathrm{mg}$ of either PEG-4000 or PEG-6000. Improved dissolution of a drug from a solid dispersion has been ascribed to several factors like amorphization of drug, increased wettability, reduced aggregation and/or agglomeration, increased effective surface area and solubilization of drug in the carrier system. ${ }^{24)}$ It was further noted that decrease in $t_{85} \%$ from the tablets prepared using $12.5 \mathrm{mg}$ PEG-4000 was significantly greater $(p<0.05)$ than that from the tablets prepared with the same amount of PEG-6000. Similarly decrease in $t_{85 \%}$ from the tablets prepared with $25 \mathrm{mg}$ of PEG-4000 was significantly greater ( $p$ $<0.1)$ than that from the tablets prepared using the same amount of PEG-6000.

A phase solubility study revealed that aqueous solubility of diazepam increased linearly as the concentration of PEG-4000 and PEG-6000 was increased from $2 \%$ to $10 \%$ : at $10 \%$ concentration, aqueous solubility of the drug increased by 2.33 and 2.27 time, respectively, as compared to the aqueous solubility $(57.65 \mathrm{mg} / \mathrm{l})$ of pure diazepam at $37^{\circ} \mathrm{C}$. The physicochemical state of solid dispersion, studied using DSC, $\mathrm{X}$ ray diffraction and FT-IR, indicated absence of formation of solid solution and complexes.
Instead, a partial transformation of crystalline drug to the amorphous state was noted. Partial amorphization together with improved wetting and solubilization of drug by the carrier could be responsible for the improved solubility and consequent dissolution of the drug. Since increase in solubility of the drug by PEG-4000 was higher than that by PEG6000 , value of $t_{85 \%}$ from the tablets prepared using solid dispersion with the former was less than from those prepared using the latter. Also, during the dissolution process, the interfacial layer between the dissolving front and the dissolution bulk medium becomes rich in carrier as the drug dissolves more rapidly. This leads to the creation of a carrier rich surface layer which acts as another barrier for the drug to diffuse prior to release into the bulk phase. If the molecular weight of the polymer is higher, the diffusion coefficient of the drug will be less and rate of dissolution of the drug will decrease. ${ }^{25}$ ) Therefore, the dissolution rate of diazepam from solid dispersions with PEG-6000 was found to be relatively slower than that with PEG-4000.

The contour plots of DT and $t_{85 \%}$ were superimposed to determine the optimized region (Fig. 1) within which any formula can satisfy the two criteria of a rapidly disintegrating, fast dissolving tablet. It was clearly noted that formulae M1, M6, M8 and M9 were outside the optimum region.

Although use of PEGs in combination restricted the values of $\mathrm{t}_{85 \%}$ within about 14 to $16 \mathrm{~min}$, the DT protracted considerably bearing one formulation in

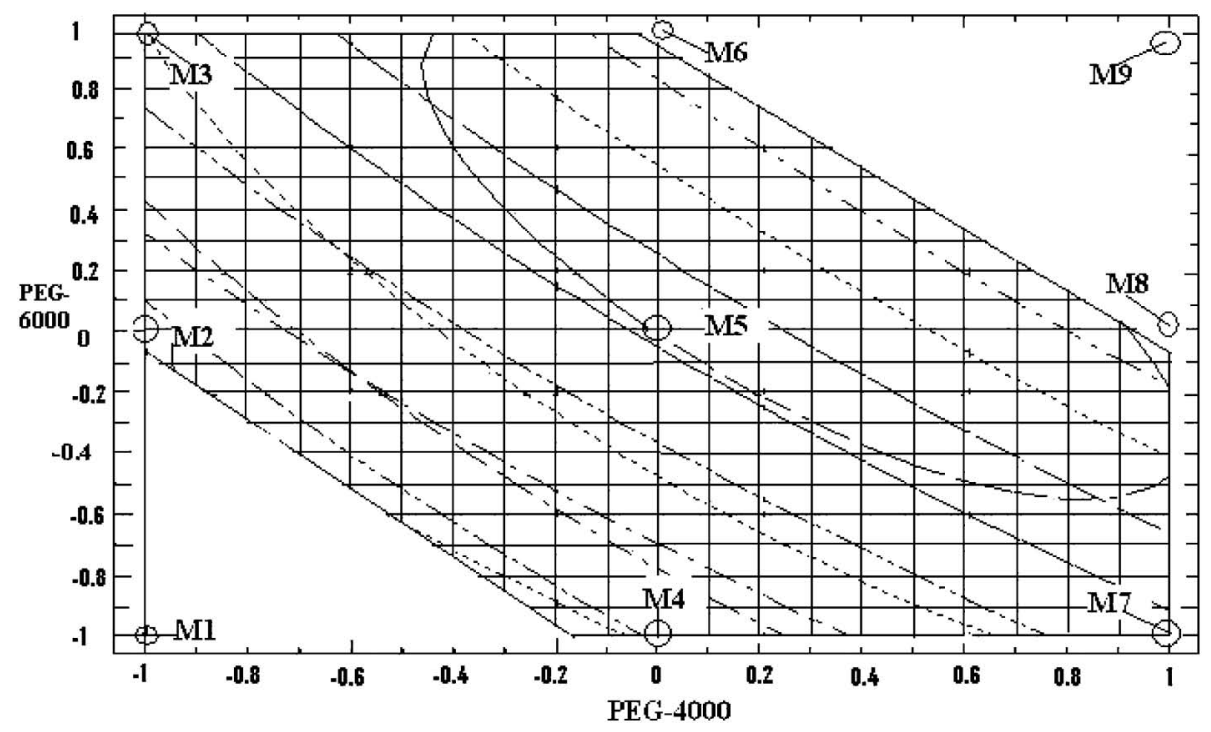

Fig. 1. Contour Plot Showing the Optimized Region 
which $12.5 \mathrm{mg}$ of each of the PEGs were used. Thus, out of the 9 formulations, 5 (M2, M3, M4, M5 and M7) met the criteria of rapidly disintegrating, fast dissolving tablet.

To assess the reliability of the statistical design and the equations that describe the influence of the amount of PEGs on DT and $\mathrm{t}_{85 \%}, 6$ formulations were selected at random from the optimized region. The predicted values and the experimental values are shown in Table 4 . The DT and $t_{85 \%}$ values of all 6 formulations satisfied the criteria of rapidly disintegrating, fast dissolving tablet. The lower values of percent relative error and the linearity (Fig. 2) between the predicted and observed responses further confirmed the reliability of the method.

\section{CONCLUSION}

Rapidly disintegrating, fast dissolving tablets of diazepam can be prepared by the existing wet granulation method using solid dispersion of the drug with PEG-4000 and/or PEG-6000 instead of the drug in its raw form. A suitable statistical approach can reduce the number of experimental runs and provide several formulation options with the desired disintegration time of tablet and dissolution time of drug contained therein. In the present study, it was revealed that several combinations of PEG-4000 and PEG-6000 in the solid dispersions can produce tablets that provide

Table 4. Comparison between Predicted and Experimental Values for the Test Formulations

\begin{tabular}{c|c|c|c|c|c|c}
\hline \hline \multirow{2}{*}{ Reponse } & \multirow{2}{*}{ Test } & \multicolumn{2}{|c|}{ Factor/level* } & Predicted \\
value & $\begin{array}{c}\text { Experimental } \\
\text { value }\end{array}$ & $\begin{array}{c}\text { \% relative } \\
\text { error }\end{array}$ \\
\cline { 3 - 6 } DT & 1 & $+0.2(15)$ & $-0.9(1.25)$ & 61.99 & 64.56 & 4.14 \\
\hline & 2 & $-0.2(10)$ & $-0.4(7.5)$ & 73.92 & 79.76 & 7.90 \\
\hline & 3 & $-0.6(5)$ & $+0.5(18.75)$ & 98.36 & 101.21 & 2.89 \\
\hline & 4 & $-0.8(2.5)$ & $+0.6(20)$ & 87.97 & 82.12 & 6.65 \\
\hline & 5 & $-0.33(8.375)$ & $+0.1(13.75)$ & 95.62 & 94.62 & 1.05 \\
\hline & 6 & $-0.52(6)$ & $+0.5(18.75)$ & 104.45 & 107.86 & 3.26 \\
\hline $\mathrm{t}_{85 \%}$ & 1 & $+0.2(15)$ & $-0.9(1.25)$ & 23.31 & 22.67 & 2.74 \\
\hline & 2 & $-0.2(10)$ & $-0.4(7.5)$ & 18.82 & 16.52 & 12.2 \\
\hline & 3 & $-0.6(5)$ & $+0.5(18.75)$ & 8.52 & 8.76 & 1.75 \\
\hline & 4 & $-0.8(2.5)$ & $+0.6(20)$ & 13.41 & 13.87 & 3.41 \\
\hline & 5 & $-0.33(8.375)$ & $+0.1(13.75)$ & 8.34 & 8.76 & 4.98 \\
\hline & 6 & $-0.52(6)$ & $+0.5(18.75)$ & 6.18 & 6.42 & 3.87 \\
\hline
\end{tabular}

* $\mathrm{X}_{1}$ : PEG 4000. $\mathrm{X}_{2}$ : PEG 6000. Figures in parentheses indicate the actual amount in $\mathrm{mg}$.
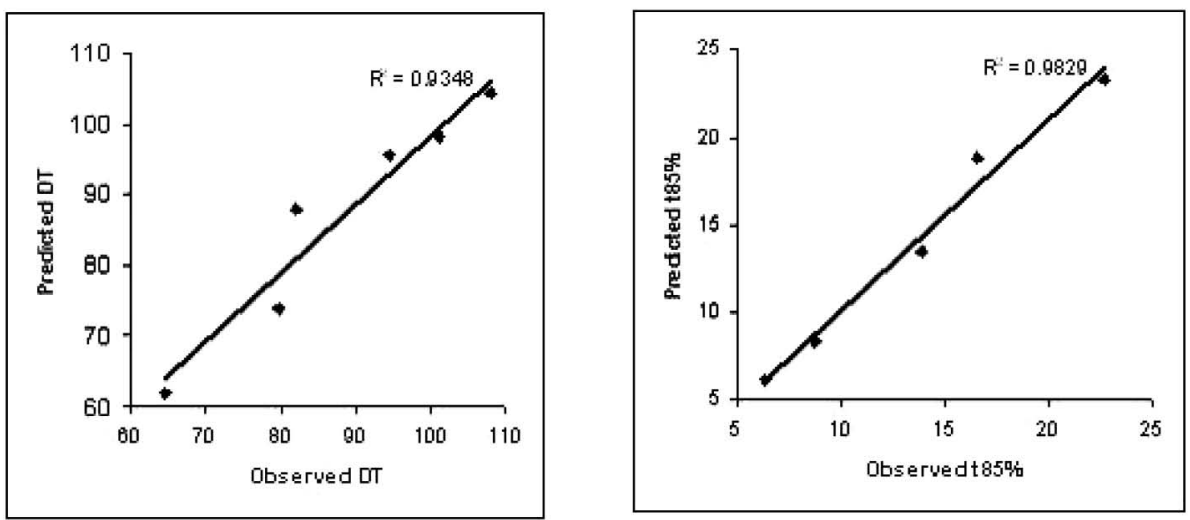

Fig. 2. Linear Correlation Graphs of the Experimentally Observed Responses with the Predicted Responses 
less than $3 \mathrm{~min}$ DT and less than $30 \mathrm{~min} \mathrm{t}_{85 \%}$. However, use of PEG-4000 alone in the lowest quantity studies provided a faster tablet disintegration and drug dissolution (32.12 $\mathrm{s}$ and $11.03 \mathrm{~min}$ ) than the use of PEG-6000 or combination of the two polyethylene glycols. Such tablets could be used in emergency treatment of anxiety disorder and epileptic seizure.

\section{REFERENCES}

1) Hoogstrate A. J., Verhoef J. C., Tuk B., Pijpers A., J. Pharm. Sci., 85, 457-460 (1996).

2) Keiko T., Yasuko O., Tsuneji N., Thorseinn L., Kozo T., Int. J. Pharm., 238, 161-170 (2002).

3) Schindler J. S., Kelly J. H., Laryngoscope, 112, 589-602 (2002).

4) Ofstehage J. C., Magilvy K., Geriatr. Nurs., 81, 238-241 (1986).

5) Motola G., Russo F., Mazzeo F., Rinaldi B., Capuano A., Rossi F., Filipelli A., $A d v$. Ther., 18, 216-222 (2001).

6) Yang L., James S. C., Joseph A., Int. J. Pharm., 235, 1-15 (2002).

7) Tripathi K. D., Essentials of Medical Pharmacology, Jaypee Brothers Medical Publishers LTD, 5th Ed., New Delhi, 9-10.

8) Li L., Gorukanti S., Choi Y. M., Kim K. H., Int. J. Pharm., 199, 65-76 (2000) .

9) Kuchekar B. S., Bhise S. B., Arumugam V., Indian. J. Pharm. Edu. 35, 150-152 (2001).

10) Loftsson T., J. Inclusion. Phenom., 44, 63-67 (2002).

11) Sugimoto M., Narisawa S., Matsubara K., Yoshino H., Nakano M., Handa T., Chem. Pharm. Bull., 54, 175-180 (2006).

12) Joshi H. N., Tejwani R. W., Davidovich M.,
Sahasrabudhe V. P., Jemal M., Bathala M. S., Varia S. A., Serajuddin A. T. M., Int. J. Pharm., 269, 251-258 (2004).

13) Mura P., Faucci M. T., Manderioli A., Bramanti G., Parrini P., Drug. Dev. Ind. Pharm., 25, 257-264 (1999).

14) Cirri M., Mura P., Rabasco A. M., Gines J. M., Moyano J. R., Drug. Dev. Ind. Pharm., 30, 65-74 (2004).

15) Serajuddin A. T. M., J. Pharm. Sci., 88, 1058-1091 (1999).

16) Bechgaard E., Gizurarason S., Hjortkjaer R. K., J. Pharm. Pharmacol., 49, 747-750 (1997).

17) Gizurarson S., Gudbrandsson F. K., Jonsson H., Bechgaard E., Biol. Pharm. Bull., 22, 425-427 (1999).

18) Rey E., Treluyer J. M., Pons G., Clin. Pharmacokin., 36, 409-424 (1999).

19) Knudsen F. U., Arch. Dis. Child., 54, 855-857 (1979) .

20) Graham C. W., Pagano R. R., Conner J. T., Anaesthesia, 33, 188-91 (1978).

21) Lehmann C., Wannarka G. L., J. Clin. Pharmacol., 48, 436-444 (2008).

22) Gilman A. G., The Pharmacological Basis of Therapeutics, Medical Publishing Division, 10th Ed, McGraw-Hill, 537.

23) Gohel M., Patel M., Amin A., Agarwal R., Dave R., Bariya N., AAPS Pharm. Sci. Tech., 5 (3) Article 36 (2004).

24) Corrigan O. I., Drug. Dev. Ind. Pharm., 11, 697-724 (1985).

25) Craig D. Q. M., Int. J. Pharm., 231, 131-144 (2002) 